\title{
Some Personality Variables in Functional Neurological Disorders
}

\author{
MARY M. ROBERTSON,${ }^{1}$ and M. R. TRIMBLE ${ }^{2,3}$ \\ ${ }^{1}$ Academic Department of Psychiatry, University College and Middlesex Hospital Schools of Medicine, \\ Mortimer Street, London, WIN $8 A A$ \\ ${ }^{2}$ The National Hospitals for Nervous Diseases, London \\ ${ }^{3}$ The Institute of Neurology, London
}

\begin{abstract}
Patients with spasmodic torticollis, writer's cramp and the Gilles de la Tourette Syndrome (GTS) were given rating scales to assess personality dimensions, especially hostility and obsessionality. The data have been compared with age and sex matched controls. Significant differences arose, especially for hostility for the GTS and writer's cramp patients, whereas those with spasmodic torticollis do not differ from controls.
\end{abstract}

\section{Introduction}

There has been an interest in the personality correlates of functional neurological disorders such as writer's cramp, spasmodic torticollis and the Gilles de la Tourette Syndrome (GTS) for many years. However, the investigations have often been confined to clinical descriptions, theoretical interpretations such as psychodynamic formulations, and lack of standardized and validated methods to define any associated psychopathology. In addition, in some studies (Sheehy and Marsden, 1982), methods used were to define psychiatric illness, as opposed to personality traits. We therefore present data on patients with various movement disorders, comparing them to normal controls, assessing specific aspects of personality, using objective validated methods of assessment.

\section{Materials and Methods}

Consecutive adult patients with spasmodic torticollis and writer's cramp, diagnosed by consultant neurologists, referred to the Department of Neuropsychiatry at the National Hospital, Queen Square and an age and sex matched group of patients with GTS, satisfying DSM III criteria and attending the same hospital, were examined. Age and sex matched normal volunteer controls with no history of psychiatric illness and currently taking no medication were obtained from the technical, secretarial and administrative personnel of the Bethlem Royal and Maudsley Joint Hospitals and the National Hospital, Queen Square. Subjects were interviewed for anamnestic and demographic data, after which they completed the Hostility and Direction of Hostility Questionnaire (HDHQ), (Foulds et al., 1960; Caine $e t$ $0953-4180 / 88 / 010023+28 \$ 3.50 / 0$ 
$a l, 1967)$ and the Hysteroid/Obsessoid Questionnaire (HOQ) (Caine and Hope, 1967). These scales, were selected to assess the direction and amount of hostility and the obsessoid/hysteroid traits in the personalities of the subjects. The data were analyzed using the Chi2-test for contingency tables, while the Mann-Whitney U-test and Kruskal-Wallis were used for examining the relationships between discrete and continuous variables. Nonparametric tests were employed because many of the continuous variables had non-normal distributions. The data were analyzed on the CDC 6600 computer at the University of London Computer Centre, using SPSS-X (Statistical package for the Social Sciences, Version X).

\section{Results}

There were 16 patients with spasmodic torticollis with a mean age of 42 years (range 19-64), 9 patients with writer's cramp with a mean age of 46 years (range 29-60) and 20 patients with GTS with a mean age of 41 years (range 18-64). There were 25 normal controls, so that each clinical group had its own age and sex matched control group. Statistical analysis confirmed no significant differences between the ages of the various groups.

The scores on the HOQ are shown in Table 1. No significant differences were found between the scores of the four groups.

The relevant scores of the HDHQ are presented in Table 2. The extrapunitive scores of $\mathrm{AH}$ (acting out hostility), $\mathrm{CO}$ (criticism of others) and sum of hostility showed significant differences between the groups, whereas the intropunitive scores of self criticism and guilt were not statistically different. Thus, patients with writer's cramp scored significantly higher on $\mathrm{AH}(U=18.0 ; p=.035)$ and $\mathrm{CO}(U=17 \cdot 5 ; p=.035)$ when compared to controls, and significantly higher on $\mathrm{CO}(U=31 \cdot 0 ; p=\cdot 018)$ when compared to patients with spasmodic torticollis. Patients with spasmodic torticollis showed no significant differences compared to controls. Patients with GTS scored significantly higher on AH $(U=92 \cdot 0 ; p=\cdot 003)$ than did controls, but no differences emerged between patients with GTS and writer's cramp or spasmodic torticollis. No differences were found between patients with GTS and the other groups with regard to CO. When the sum of hostility scores were analyzed, GTS patients scored significantly

TABLE 1. HOQ Scores

\begin{tabular}{lccc}
\hline & Mean & Median & Range \\
\hline Spasmodic Torticollis & 25 & 24 & $18-36$ \\
Writer's Cramp & 24 & 23 & $18-33$ \\
Gilles de la Tourette & 26 & 23 & $11-31$ \\
Controls & 24 & 25 & $15-32$ \\
Normative Data $\dagger$ 23.5-24 & & & \\
\hline
\end{tabular}

†Caine and Hope, 1967. 
TABLE 2. HDHQ Scores

\begin{tabular}{|c|c|c|c|c|c|c|}
\hline \multirow[b]{2}{*}{ Group } & \multicolumn{2}{|c|}{ Acting out hostility } & \multicolumn{2}{|c|}{ Criticism of others } & \multicolumn{2}{|c|}{ Sum of hostility } \\
\hline & Median & Range & Median & Range & Median & Range \\
\hline \multicolumn{7}{|l|}{ Spasmodic } \\
\hline Torticollis & $4 \cdot 0$ & $1-10$ & $3.0 *$ & $0-8$ & $15 \cdot 0$ & $4-32$ \\
\hline Writer's Cramp & $5 \cdot 0 *$ & $2-6$ & $7 \cdot 0$ & $3-7$ & $20 \cdot 0$ & $8 \cdot 25 *$ \\
\hline \multicolumn{7}{|l|}{ Gilles de la } \\
\hline Tourette & $5 \cdot 5^{*}$ & $2-10$ & $5 \cdot 0$ & $0-11$ & $22 \cdot 5$ & $5-33^{*}$ \\
\hline $\begin{array}{l}\text { Controls } \\
\text { Normative D }\end{array}$ & $3 \cdot 0 * *$ & $2-8$ & $4 \cdot 0$ & $0-8$ & $13 \cdot 0$ & $5-27 * *$ \\
\hline
\end{tabular}

$*<0.05$

$* *<0.01$

$* * *<0.005$

†Caine et al., 1967

higher than patients with both writer's cramp and spasmodic torticollis $(U=121 ; p=\cdot 03)$ and controls $(U=107 ; p=\cdot 01)$, while no differences emerged between writer's cramp or spasmodic torticollis patients and controls.

\section{Discussion}

These data suggest that, with regard to the three movement disorders we have examined, differences between personality profiles may exist. The main finding was in relation to hostility scores, patients with GTS being significantly higher on some of these measures than controls and the other patient groups. No abnormalities were found for the spasmodic torticollis patients, while the writer's cramp group did show higher acting out hostility.

It is now generally agreed that writer's cramp and spasmodic torticollis fall within the spectrum of focal dystonias (Fahn and Eldridge, 1976; Marsden, 1976) and suffer little from formal psychiatric illness (Sheehy and Marsden, 1982; Patterson and Little, 1943). However, advocates for a "psychogenic origin", generally discussed in psychoanalytic terms (Murphy and Chasen, 1956; Auerbach and Gliebe, 1942; Mitscherlich, 1971) for both conditions exist, as do suggestions of particular personality types (Mears, $1971 a, b$; Mathews et al., 1978; Crisp and Moldofsky, 1965).

There have been indications (Mears 1971a,b; Tibbetts, 1971; ChoppyJacolin et al., 1977) that patients with spasmodic torticollis show increased neuroticism, but this has been disputed (Cockburn, 1971; Hughes and McLellan, 1985). Others (Herz and Glaser, 1949) have commented on the non specific abnormal personality of patients with spasmodic torticollis. Clinical impressions, predominantly from the psychoanalytic literature, have noted patients to harbour repressed hostility (Murphy and Chasen, 1956; Auerbach and Gliebe, 1942; Mitscherlich, 1971; Mendelson, 1955; Whiles, 1940) and from interpretations of the Rorschach projective test (Cleveland, 1959), hostility has been found to be higher than normal. 
However, in one study using rating scales Mathews et al. (1978) reported that the sum and direction of hostility on the HDHQ were no different from population norms, although no control group was used.

Patients with writer's cramp have been noted to have difficulty in expressing anger and hostility (Crisp and Moldofsky, 1965), while in a series of experiments on patients with various psychiatric diagnoses (Shagass and Malmo, 1954; Malmo et al., 1950), including one with writer's cramp (Malmo et al., 1950), specifically and significantly high forearm tension was measured during electromyographic investigations when the subjects discussed topics concerning anger and hostility.

With regard to GTS, much of the early literature relates to aggression, the tic either representing some form of internalized unexpressed aggression, either being seen as a defence against aggressive impulses or as an outlet for unacceptable aggressive feelings (Trimble and Robertson, 1987). Moreover, two case studies employing the Rorschach projective test (Dunlap, 1960; Downing et al., 1964) found that tics were acceptable methods of expressing unacceptable hostility. Investigations using the MMPI (Shapiro et al., 1972, 1978) have found evidence of "inhibition of hostility" in $34 \%$ of G'TS subjects.

Thus, overall there has been some uniformity throughout the literature with respect to all three disorders, notably with suggestions of increased hostility in these particular patient groups.

In this study, our GTS patients had significantly higher hostility as measured by the HDHQ total score, than patients with writer's cramp, spasmodic torticollis and controls, and no differences between the latter three groups emerged.

Patients with writer's cramp had significantly higher $\mathrm{AH}$ than did controls and significantly higher $\mathrm{CO}$ than did those with spasmodic torticollis, both $\mathrm{AH}$ and $\mathrm{CO}$ being extrapunitive measures of hostility. Thus, both GTS patients and those with writer's cramp have overt aggressive behaviour and possibly covert anger (writer's cramp) which distinguishes those with spasmodic torticollis. Our data failed to support the psychoanalytic theories of aggression in motor disorders which emphasize repressed hostility, the direction of the changes in our population being more notably the extrapunitive scores. An alternative explanation is that the rating scales are not specific enough or do not measure accurately.

Another personality feature commonly discussed in these three conditions is obsessionality. Patients with spasmodic torticollis (Mears, 1971a) and writer's cramp (Crisp and Moldofsky, 1965; Bindman and Tibbetts, 1977) have been shown to have obsessional personality traits, but not obsessional illness. Mathews et al. (1978) found no deviation from population norms in the scores of patients with spasmodic torticollis with respect to both obsessional traits and symptoms, but no control group was employed. There is a growing literature on the increased occurrence of obsessive compulsive phenomena in patients with GTS (Trimble and Robertson, 1987; Frankel et al., 1986). Trimble and Robertson (1987), found associations between these and other central features of the syndrome including 
coprolalia and echophenomena. In the present study the HOQ was employed, which measures the spectrum/dimension of hysteroid-obsessoid personality traits as opposed to illness or symptoms. The scores for all four groups were found not to differ significantly and indeed to not deviate from the given population norms (see Table 1). One interpretation of these data is that there is no increase of obsessional traits in the patients with these disorders. This is in contrast to the finding of significant obsessional illness on a larger sample of GTS patients (Robertson et al., 1988; Frankel et al., 1986). These conflicting findings may be partly explained by the fact that different rating scales measuring different aspects of obsessionality were employed, such as the Sandler-Hazari scale (Mears, 1971), the Leyton Obsessional Inventory (Matthews et al., 1978; Robertson et al., 1988) and the HOQ (present study), while in others (Matthews et al., 1978) there were no control groups. It is of interest, however, that the GTS patients not only had a wider range of HOQ scores, but they were also lower, that is, tending towards the obsessional.

In conclusion, it would appear that patients with spasmodic torticollis do not differ significantly from normal controls with respect to personality variables such as hostility and obsessionality. In contrast, patients with writer's cramp show hostility, while the group of GTS patients have increased total and extrapunitive hostility. These personality variables may be intimately related to the pathogenesis and clinical presentation of the disorders, and hint at differences between spasmodic torticollis and writer's cramp that may reflect on the classification of both as focal dystonias.

\section{Acknowledgements}

We would like to thank all patients and staff who participated in the study and Mrs. Penny Nicholson for typing the manuscript.

\section{References}

Auberbach, A. and Gliebe, P. A. (1942). The psychiatric aspects of Spasmodic Torticollis. Clinics, 1, 972-979.

Bindman, E. and Tibbetts, R. W. (1977). Writer's cramp-a rational approach to treatment? British Journal of Psychiatry, 131, 143-8.

Caine, T. M. and Hope, K. (1967). "Manual of the Hysteroid Obsessoid Questionnaire (HOQ)". University of London Press, London.

Caine, T. M., Foulds, G. A. and Hope, K. (1967). "The Manual of the Hostility and Direction of Hostility Questionnaire". University of London Press, London.

Choppy-Jacolin, Ferrey, G. and Demaria, C. (1977). A psychometric study of 34 patients afflicted with spasmodic torticollis. Acta neurologica scandanavica, 55, 483-492.

Cleveland, S. E. (1959). Personality dynamics in torticollis. Journal of Nervous and Mental Disease, 129, 150-161.

Cockburn, J.J. (1971). Spasmodic Torticollis. A psychogenic condition? Psychosomatic Research, 15, 471-477.

Crisp, A. H. and Moldofsky, H. (1965). A psychosomatic study of writer's cramp. British Journal of Psychiatry, 111, 841-858.

Downing, R. W., Comer, N. L. and Ebert, J. N. (1964). Family Dynamics in a case of Gilles de la Tourette Syndrome. Journal of Nervous and Mental Disease, 138, 584-557. 
Dunlap, J. R. (1960). A case of Gilles de la Tourette disease (Maladie des Tics): A study of the intrafamily dynamics. Fournal of Nervous and Mental Disease, 130, 340-344.

Fahn, S. and Eldridge, R. (1976). Definition of dystonia and classification of the dystonic states. In "Advances in Neurology", Vol. 14 (Ed. R. Eldridge and S. Fahn), Raven Press, New York.

Frankel, M., Cummings, J. L., Robertson, M. M., Trimble, M. R., Hill, M. A. and Benson, F. (1986). Obsessions and compulsions in Gilles de la Tourette's Syndrome. Neurology, 36, 378-382.

Foulds, G. A., Caine, T. M. and Creasey, M. A. (1960). Aspects of extra and intropunitive expression in mental illness. Mental Science, 106, 599-610.

Herz, E. and Glaser, G. H. (1949). Spasmodic Torticollis-II. Clinical evaluation. Archives of Neurology and Psychiatry, 61, 227--239.

Hughes, M. and McLellan, D. L. (1985). Increased co-activation of the upper limb muscles in writer's cramp. Journal of Neurology, Neurosurgery and Psychiatry, 48, 782-787.

Malmo, R. B., Shagrass, C. and Davis, F.H. (1950). Symptom specificity and bodily reactions during psychiatric interview. Psychosomatic Medicine, 12, 363-376.

Malmo, R. B., Smith, A. A. and Kohlmeyer, W. A. (1956). Motor manifestation of conflict in interview: a case study. Journal of Abnormal and Social Psychology, 52, 268-271.

Marsden, C. D. (1976). Dystonia: the spectrum of the disease. In "The Basal Ganglia", (Ed. M. D. Yahr) Raven Press, New York.

Matthews, W. B., Beasley, P., Parry-Jones, W. and Garland, G. (1978). Spasmodic torticollis: a combined clinical study. Neurology, Neurosurgery and Psychiatry, 41, 485-492.

Mears, R. (1971a). Obsessionality, the Sandler-Hazari scale and spasmodic torticollis. British Journal of Medical Psychology, 44, 181-182.

Mears, R. (1971b). Features which distinguish groups of spasmodic torticollis. Psychosomatic, $15,1-11$.

Mendleson, J. (1955). Psychodynamics in a case of retrocollis. Diseases of the Nervous System, 16, $339-342$.

Mitscherlich, M. (1971). Spasmodic Torticollis. Psychotherapy and Psychosomatics, 19, 62-75.

Murphy, W. F. and Chasen, M. (1956). Spasmodic Torticollis-a case presentation and discussion. Psychoanalytic Review, 43, 18-33.

Patterson, R. M. and Little, S. C. (1943). Spasmodic Torticollis. Journal of Nervous and Mental Disease, 98, 571-599.

Robertson, M. M., Trimble, M. R. and Lees, A. J. (1988). The psychopathology of the Gilles de la Tourette Syndrome: A phenomenological analysis. British fournal of Psychiatry, 152, 383-390.

Shagass, C. and Malmo, K. B. (1954). Psychodynamic themes and localized muscular tension during psychotherapy. Psychosomatic Medicine, 16, 295-314.

Shapiro, A. K., Shapiro, E., Wayne, H. L. and Clarkin, J. (1972). The psychopathology of Gilles de la Tourette Syndrome. American Journal of Psychiatry, 129, 427-434.

Shapiro. A. K., Shapiro, E. S., Bruun, R. D. and Sweet, R. D. (1978). "Gilles de la Tourette Syndrome". Raven Press, New York.

Sheehy, M. P. and Marsden, C. D. (1982). Writers' Cramp-a focal dystonia. Brain, 105, $461-480$.

Tibbetts, R. W. (1971). Spasmodic 'Torticollis. Psychosomatic Research, 15, 461-469.

Trimble, M. R. and Robertson, M. M. (1987). 'The psychopathology of tics. In "Modern 'Trends in Neurology", Movement Disorders, Vol. 2. (Eds. C. D. Marsden and S. Fahn) Butterworths, Sevenoaks, Kent, 406-422.

Whiles, W. H. (1940). Treatment of spasmodic torticollis by psychotherapy. British Medical Journal, 969-971. 


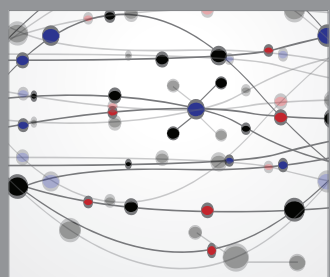

The Scientific World Journal
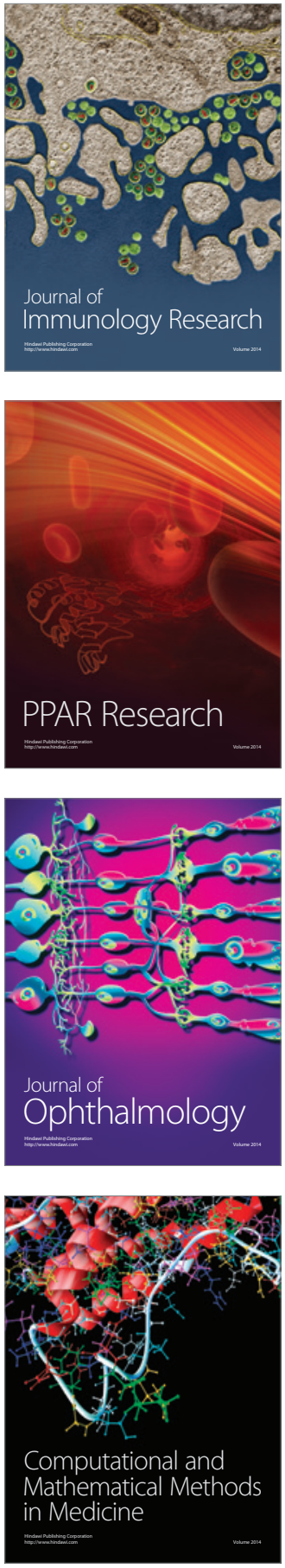

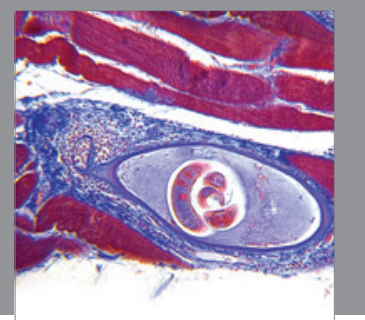

Gastroenterology

Research and Practice
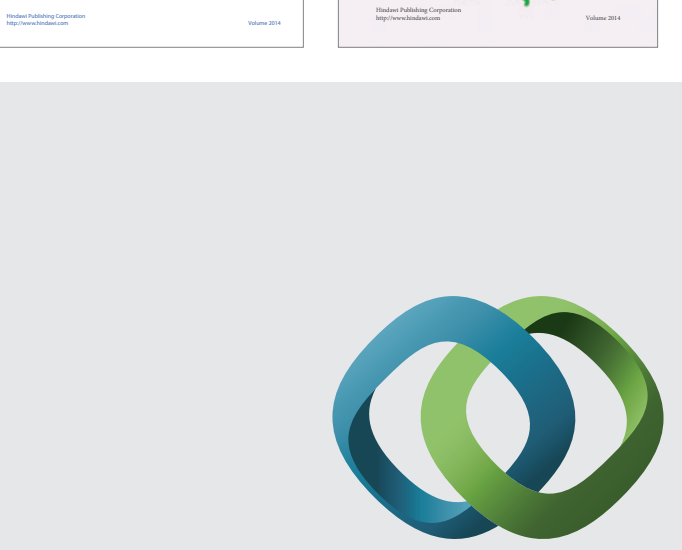

\section{Hindawi}

Submit your manuscripts at

http://www.hindawi.com
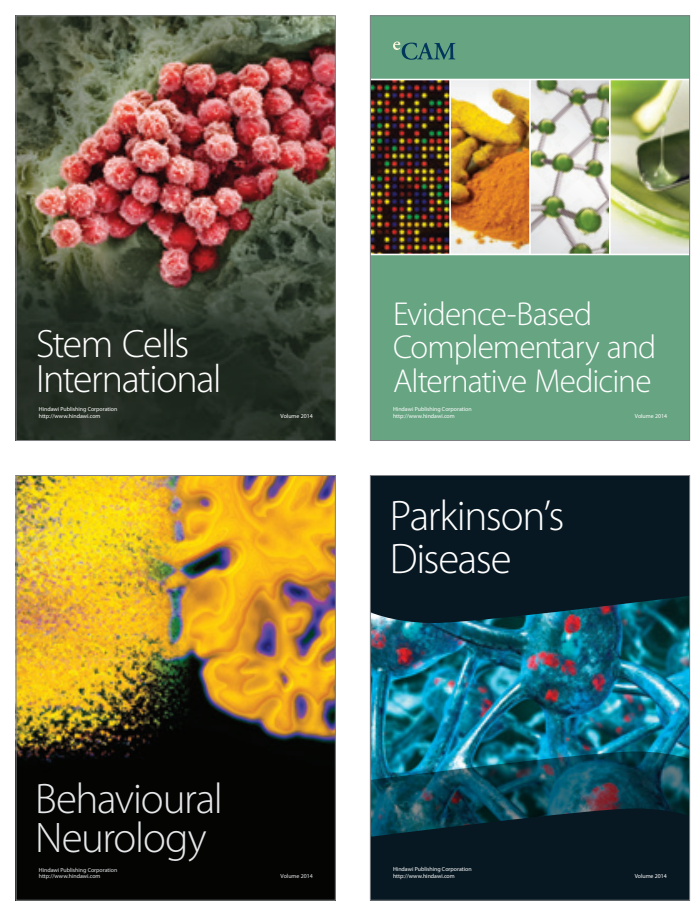

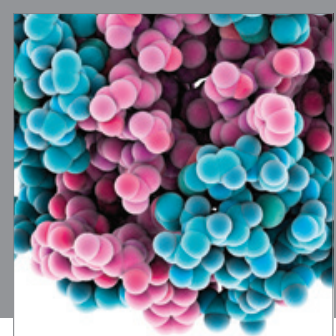

Journal of
Diabetes Research

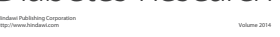

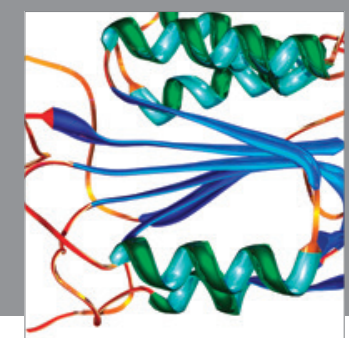

Disease Markers
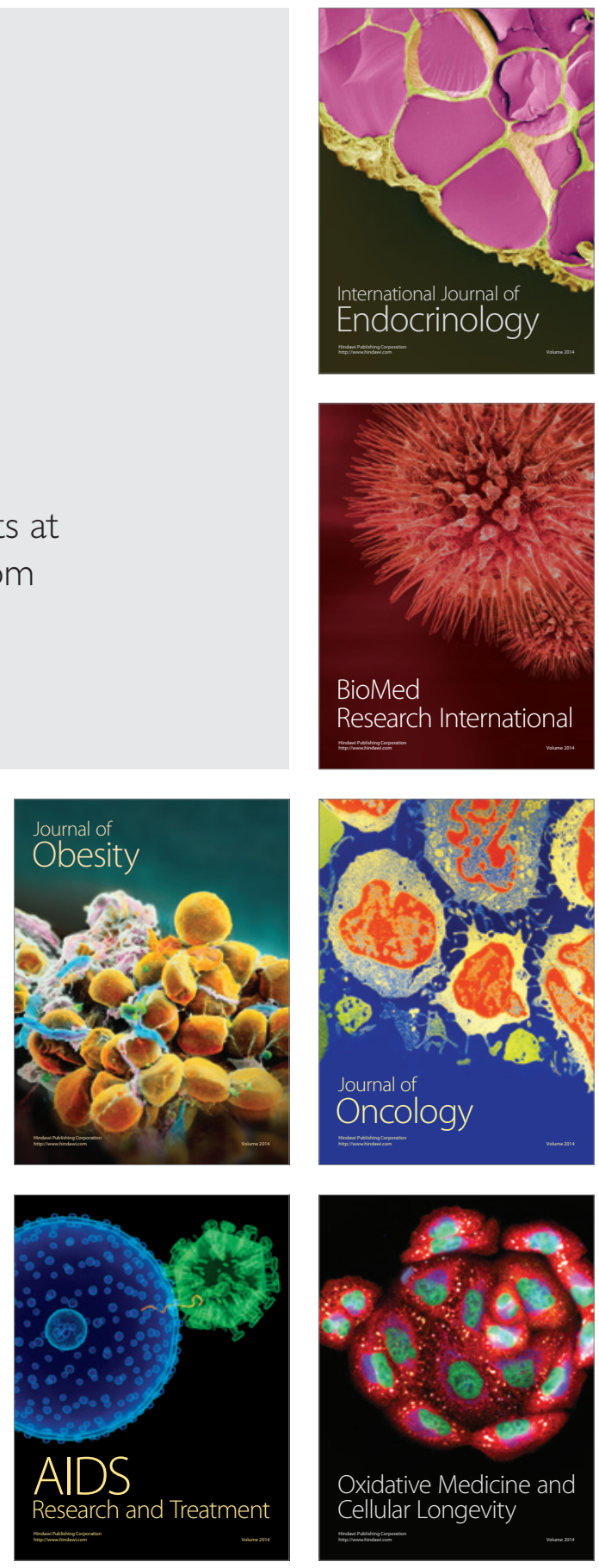